\title{
Aproveitamento energético e ações consorciadas no contexto dos resíduos sólidos urbanos
}

\section{Energy utilization and consortium actions in the context of urban solid waste}

Data de entrada: 24/07/2017

Data de aprovação: $14 / 06 / 2018$

Flávio Aguiar Folletto ${ }^{1}$ | Luciana Paulo Gomes ${ }^{1 *}$ | Marcelo Oliveira Caetano ${ }^{1}$

DOI: https://doi.org/10.36659/dae.2020.006

ORCID ID

Folletto F.A iD https://orcid.org/0000-0002-0692-6168

Gomes L.P (iD https://orcid.org/0000-0003-4542-1143

Caetano M.O iD https://orcid.org/0000-0002-0920-1971

\section{Resumo}

Entre as etapas que integram o gerenciamento de Resíduos Sólidos Urbanos (RSU), a destinação final em aterros sanitários tem recebido menor atenção na gestão dos processos, quando comparados à coleta e ao transporte de resíduos. A associatividade entre municípios ou consórcios públicos tem se mostrado uma alternativa emergente, não só para com os aspectos econômicos, mas também visando a possibilidade de aproveitamento energético. Este estudo buscou avaliar alternativas para a valoração energética no escopo dos RSU, abordando uma relação simbiótica com os geradores, localizados na Bacia Hidrográfica do Rio dos Sinos. Os arranjos intermunicipais possibilitaram vislumbrar a possibilidade de gerir consorciadamente quatro ordenamentos, reduzindo os custos de instalação e operação de aterros sanitários, além da expectativa favorável ao reaproveitamento energético, a partir do biogás gerado nesses sistemas.

Palavras-chave: Resíduos Sólidos Urbanos. Aproveitamento energético. Arranjos intermunicipais.

\section{Abstract}

Among the steps that integrate the management of Municipal Solid Waste (MSW), the disposal in landfills has received less attention in the management of processes, when compared to the collection and transportation of waste. The associativity between municipalities or public consortia has shown to be an emerging alternative, not only to the economic aspects, but also, aiming at the possibility of energy utilization. This study search to evaluate alternatives to energy assessment within the RSU, addressing a symbiotic relationship with the generators, located in the Rio dos Sinos River Basin. Intercity arrangements made it possible to glimpse the possibility of managing consortium four systems, reducing installation and operating costs of landfills, as well as favorable expectations to reuse energy from the biogas, generated in these systems.

Keywords: Urban solid wastes. Energy recovery. Intercity arrangements.

\footnotetext{
${ }^{1}$ Unisinos - Universidade do Vale do Rio dos Sinos. São Leopoldo (RS), Brasil.

* Autor correspondente: lugomesaunisinos.br.
} 


\section{INTRODUÇÃO E OBJETIVO}

Equacionar a gestão e o gerenciamento de Resíduos Sólidos Urbanos (RSU) tornou-se um grande desafio não só para a administração pública mas também para a sociedade. A disposição final de RSU demanda constante expansão dos sistemas operacionais, frente ao crescente aumento populacional e consequente incremento dos volumes diários de resíduos gerados.

Segundo dados do Instituto Brasileiro de Geografia e Estatística (IBGE), no Brasil, entre os seus 204 milhões de habitantes estimados para o ano de 2015 , cerca de $85 \%$ estão residindo em áreas urbanas. Além disso, o cenário econômico nacional da última década aponta para um crescimento médio anual per capita de $2,4 \%$, resultando em um incremento populacional de $12,87 \%$ (IBGE, 2015). Nesse mesmo período, a geração de resíduos sólidos urbanos teve um aumento aproximado de 36\% (JUCÁ, 2014).

Dentre as etapas do gerenciamento dos RSU, historicamente, têm sido alvo principal dos gestores apenas a coleta e o transporte, especialmente em áreas urbanas. Para tanto, basta analisar os valores relacionados à cobertura dos serviços de coleta que se estendem a mais de $90 \%$ da população, enquanto a destinação final ambientalmente adequada, em aterros sanitários, atinge 58,7\% dos resíduos (ABRELPE, 2016).

Para Suzuki e Gomes (2009), no Brasil, as políticas e investimentos públicos não cobrem a demanda para a área de gerenciamento de resíduos sólidos urbanos gerados. Porém a eficiência administrativa neste quesito deve ser implantada e mantida pelo órgão público local, assim como a capacitação técnica profissional, além do envolvimento e da conscientização da sociedade.

Zveibil (2011) destaca que os consórcios públicos entre municípios possibilitam gerir recursos, sejam eles humanos ou financeiros, entre os cooperados. Essa ferramenta acaba viabilizando a implantação de ações, programas ou projetos comuns aos integrantes. Essa forma de cooperação permite ainda que os entes federativos possam prestar serviços de qualidade, abrindo mão de concessões ou terceirizações.

Neto et al. (2011) estimaram os custos de implantação de aterros sanitários em municípios, considerando os custos por habitante. Para atender a uma população estimada em 10.000 habitantes, seriam gastos o valor de $\mathrm{R} \$$ $184,06 /$ hab, enquanto para uma população de projeto de 250.000 habitantes a soma seria de $\mathrm{R} \$ 30,16 / \mathrm{hab}$.

Essas conclusões demonstram claramente a relação inversa do porte do empreendimento com os custos per capita. Dentro dessa premissa, a formação e a implantação de consórcios públicos intermunicipais para gerir a disposição final de resíduos sólidos urbanos surgem como uma alternativa viável economicamente. Além disso, essa possibilidade reduz a demanda por áreas ambientalmente favoráveis, otimizando a gestão ambiental dos resíduos.

Agregado a esses conceitos, podem ser propostas formas de aperfeiçoar ainda mais o processo de destinação final de RSU. Dependente obviamente de estudos de viabilidade técnica e econômica, uma alternativa é a geração de energia elétrica por meio do biogás. No entanto, segundo Barros, Filho e Silva (2014), essa forma de exploração só se torna viável com uma população superior a 200.000 habitantes, o que direciona ainda mais a busca por alternativas consorciadas.

Santos; Barros e Filho (2015) desenvolveram um estudo considerando parâmetros econômicos, ambientais e energéticos no aproveitamento do biogás em aterros sanitários. Além de atestarem a viabilidade e caracterizarem a conversão energética como uma ação sustentável, os autores 
enaltecem ainda benefícios como a produção de energia por meio de uma fonte renovável, geração descentralizada e diminuição da emissão de gases de efeito estufa.

A partir dessa realidade, poderia ser estabelecida uma relação simbiótica entre a geração de RSU e o retorno, pós-tratamento, desses resíduos na forma de energia elétrica. Para Tanimoto e Kiperstok (2004), a relação simbiótica, ou apenas simbiose, vem da natureza, onde dois ou mais seres de espécies diferentes convivem de forma que a soma de esforços coletivos supera a soma dos esforços individuais. Esse tipo de relacionamento promove uma interação social entre os participantes que pode se estender à vizinhança de maneira benéfica.

O conceito de Simbiose como ferramenta de gestão ambiental surgiu na área da Ecologia In- dustrial, assim como a Química Verde e o Ecoparque, entre outros. De maneira geral, a Simbiose busca, por exemplo, atribuir valores aos resíduos em função dos componentes presentes, com potencial de reaproveitamento em outra atividade que possa absorvê-la como matéria-prima ou insumos em outro ciclo produtivo (TANIMOTO e KIPERSTOK, 2004).

$\mathrm{Na}$ área industrial, a Simbiose visa à obtenção de vantagem competitiva, envolvendo entidades por meio de intercâmbio de subprodutos (CHERTOW, 2007). Para o caso de produção de energia a partir de resíduos, a interação é semelhante: um subproduto é empregado para geração de eletricidade, auxiliando ainda a diminuição do consumo líquido empregado justamente na produção destes resíduos (Fig. 1).

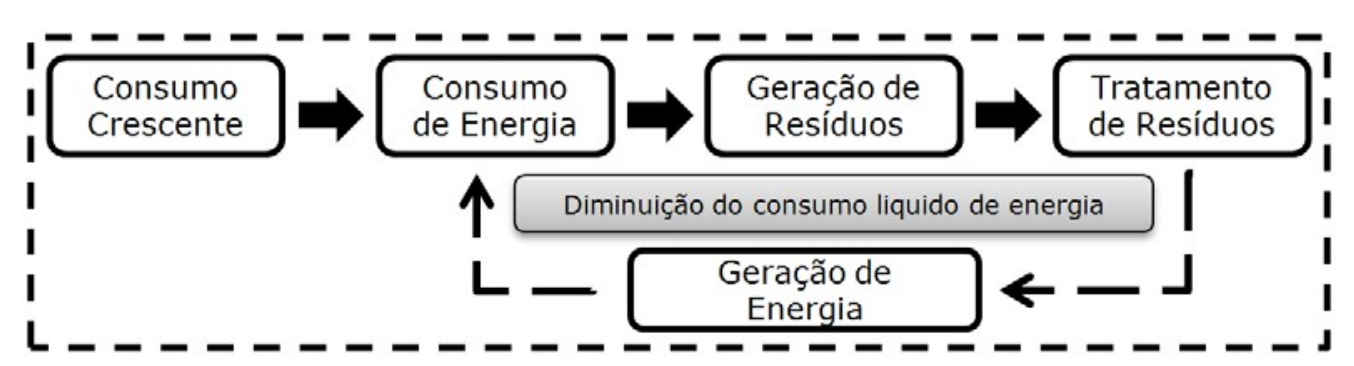

Figura 1: Energia a partir do tratamento de resíduos

Fonte: Santos; Barros e Filho, 2015.

Os conceitos da área industrial relativos à simbiose podem se estender para o gerenciamento final de resíduos. Pinto (2007) destaca que as relações podem ser estabelecidas entre núcleos regionais e não necessariamente somente dentro do parque industrial, por exemplo. Dessa forma, o importante é que as relações sinérgicas oferecidas dentro de uma região ofereçam eficiência para com os programas e relações operacionais.

Uma das formas de desenvolvimento de simbiose industrial que pode ser extrapolada para gestão final consorciada de RSU é a distribuição geográ- fica das atividades (geração e disposição final). Ou seja, a possibilidade de avaliar a localização das fontes geradoras e definir a abrangência das áreas de interesse. No gerenciamento de RSU, este é um importante pré-requisito a ser avaliado em função do transporte de resíduos até a disposição final em aterros sanitários.

Entre as ferramentas de gestão territorial, os Sistemas de Informações Geográficas (SIG) tem evoluído nos últimos anos. Para Ghilani e Wolf (2013), o SIG permite acesso à informação múltipla e integrada numa única base de dados. Dessa 
forma, possibilita a elaboração de diferentes cenários alternativos e a simulação dos seus efeitos espaciais. Essa alternativa ajuda, por exemplo, a melhorar as definições de medidas de planejamento a serem aplicadas na área pretendida.

Para Smith, Goodchild e Longley (2015), o gerenciamento de um SIG envolve operações como sobreposição de mapas (combinação de dois ou mais mapas ou camadas) e buffer simples (delimitação de regiões em um mapa, a uma determinada distância de um ou mais recursos, como cidades, estradas ou rios, entre outras operações básicas do sistema). A possibilidade de gerir essas informações ganhou impulso nas áreas das ciências ambientais.

A partir desse cenário, o presente estudo buscou identificar arranjos intermunicipais para a etapa final de gerenciamento de RSU, na Bacia Hidrográfica do Rio dos Sinos. De acordo com os dados da Secretaria Estadual de Meio Ambiente do Estado do Rio Grande do Sul - SEMA/RS, geograficamente, a Bacia Hidrográfica do Rio dos Sinos localiza-se na porção nordeste do Estado. Abrange uma área aproximada de $3.747 \mathrm{~km}^{2}$, englobando, total ou parcialmente, 32 municípios. Limita-se ao norte pela coordenadas geográficas $29^{\circ} 20^{\prime}$ a $30^{\circ} 10^{\prime}$ de latitude Sul e $50^{\circ} 15^{\prime}$ a $51^{\circ} 20^{\prime}$ de longitude Oeste.

O trabalho espacializou possíveis cenários, integrando mais de um município em um raio de 10 $\mathrm{km}$ das áreas urbanas. $\mathrm{O}$ objetivo foi identificar possíveis arranjos que possam ser geridos de forma consorciada entre os municípios da Bacia, assim como considerar uma população mínima de projeto de 200.000 habitantes, com vista ao aproveitamento energético do biogás gerado em aterros sanitários.

\section{METODOLOGIA}

Para o desenvolvimento deste trabalho foram utilizados softwares de processamento de dados em ambiente SIG. Neste caso, foram utilizados os programas computacionais ArcGis 10, Global Mapper 15, software topográfico Topo EVN e Google Earth Pro, para tratamento e geração de dados. Os dados digitais são oriundos da SEMA/ RS, por meio de seus departamentos especializados, como é o caso da Fundação Estadual de Proteção Ambiental - FEPAM.

A delimitação das áreas urbanas foi digitalizada, incluindo pequenos aglomerados populacionais fora dos núcleos urbanos de cada município. Esse procedimento objetivou englobar todas as regiões urbanizadas de cada município, para onde se estende a coleta de resíduos sólidos urbanos. A digitalização das áreas citadas foi realizada a partir de imagens disponibilizas por softwares livres, contendo atributos espaciais, resultando em escalas de detalhe inferiores a 1:50.000.

Concluído o processo de obtenção de dados e mapeamento, um círculo com raio de $10 \mathrm{~km}$ _recomendação técnica de projeto para distância máxima a ser percorrida entre o gerador e o local de disposição final, descritos por Zveibil (2011)_ poderá responder quantos e quais municípios estariam englobados naquelas áreas.

A partir dessa análise conjunta, foram geradas imagens ilustrativas e tabelas com arranjos intermunicipais possíveis de serem geridos em conjunto entre as municipalidades. Estudaramse apenas as alternativas que contemplam o mínimo de 200.000 habitantes para cada consórcio, segundo a viabilidade econômica para geração de energia elétrica por meio do Biogás, segundo os trabalhos de Neto et al., 2011; Barros et al., 2014.

O estudo compreendeu 5 etapas distintas e sequenciais, apresentadas a seguir, no Quadro 1. 
Quadro 1: Métodos e referenciais teóricos empregados.

\begin{tabular}{|c|c|}
\hline Etapas & Método/Fonte de dados \\
\hline (1) Organização da base cartográfica digital & $\begin{array}{l}\text { Estudo desenvolvido para gerenciamento consorciado; Base digital - SEMA } \\
\text { (2015); Softwares ArcGis 10; Global Mapper 15 - Escalas 1:50.000 }\end{array}$ \\
\hline (2) Levantamento da população residente & $\begin{array}{l}\text { Plano Regional de Gestão Integrada de Resíduos Sólidos dos Municipios } \\
\text { Integrantes do Consórcio Pró- Sinos (2012). IBGE (2015) }\end{array}$ \\
\hline $\begin{array}{l}\text { (3) Verificação das áreas de abrangência dos municípios em um raio de } \\
10 \text { km (SIG) }\end{array}$ & Zveibil (2011); Mapeamento - SIG (Softwares ArcGis 10; Global Mapper 15) \\
\hline (4) Avaliação de Cenários resultantes e arranjos intermunicipais (SIG) & Variação em áreas de abrangência alternando resultados e validando arranjos \\
\hline (5) Elaboração imagens ilustrativas relacionando possíveis consórcios (SIG). & Softwares ArcGis 10; Global Mapper15 \\
\hline
\end{tabular}

\section{RESULTADOS E DISCUSSÃO}

De acordo com o IBGE (2015), a estimativa para a população total nos municípios que compõem a Bacia Hidrográfica do Rio dos Sinos no ano de 2015 é de 2.206.927 habitantes. Ressalta-se ainda que nem todos os municípios estão inte- gralmente inseridos na Bacia, sendo que em alguns casos os limites dividem áreas urbanas, assim como rurais. Para este estudo, considerou-se a população total da Bacia Hidrográfica do Rio dos Sinos, totalizando 32 municípios, apresentados na Tabela 1.

Tabela 1: Municípios relacionados no estudo.

\begin{tabular}{|c|c|c|c|c|}
\hline & Município & $\begin{array}{l}\text { População estimada } \\
2015 \text { - (hab.) }\end{array}$ & $\begin{array}{c}\text { RSU Gerado em } 2012 \\
\text { ton.dia }{ }^{-1}\end{array}$ & $\begin{array}{l}\text { Geração per capita } \\
\text { kg.hab.dia }{ }^{-1}\end{array}$ \\
\hline 1 & Araricá & 5.301 & 2,1 & 0,41 \\
\hline 2 & Cachoeirinha & 125.975 & 71,8 & 0,57 \\
\hline 3 & Campo Bom & 64.171 & 28,23 & 0,44 \\
\hline 4 & Canela & 42.411 & 31,8 & 0,75 \\
\hline 5 & Canoas & 341.343 & 293,5 & 0,86 \\
\hline 6 & Capela de Santana* & 11.289 & 6,8 & 0,61 \\
\hline 7 & Caraá & 7.863 & 2,1 & 0,27 \\
\hline 8 & Dois Irmãos & 30.175 & 17,8 & 0,59 \\
\hline 9 & Estância Velha & 46.444 & 20,9 & 0,45 \\
\hline 10 & Esteio & 83.984 & 52,9 & 0,63 \\
\hline 11 & Glorinha & 7.518 & 4,6 & 0,62 \\
\hline 12 & Gramado & 34.605 & 30,1 & 0,87 \\
\hline 13 & Gravataî* & 272.257 & 166,0 & 0,61 \\
\hline 14 & Igrejinha & 34.341 & 28,1 & 0,82 \\
\hline 15 & Ivoti"* & 22.012 & 13,4 & 0,61 \\
\hline 16 & Nova Hartz & 20.035 & 8,8 & 0,44 \\
\hline 17 & Nova Santa Rita & 25.700 & 22,6 & 0,88 \\
\hline 18 & Novo Hamburgo & 248.694 & 186,5 & 0,75 \\
\hline 19 & Osório* & 43.897 & 26,8 & 0,61 \\
\hline 20 & Parobé & 55.486 & 41,0 & 0,74 \\
\hline 21 & Portão & 33.994 & 13,5 & 0,40 \\
\hline 22 & Riozinho & 4.571 & 2,9 & 0,65 \\
\hline 23 & Rolante & 20.712 & 10,5 & 0,51 \\
\hline 24 & Santa Maria do Herval* & 6.328 & 3,8 & 0,61 \\
\hline 25 & Santo Antônio da Patrulha & 41.977 & 23,0 & 0,55 \\
\hline 26 & São Francisco de Paula & 21.551 & 14,6 & 0,68 \\
\hline 27 & São Leopoldo & 228.370 & 180,4 & 0,79 \\
\hline 28 & São Sebastião do Caî* & 24.676 & 15,0 & 0,61 \\
\hline 29 & Sapiranga & 79.560 & 50,1 & 0,63 \\
\hline 30 & Sapucaia do Sul & 138.357 & 127,3 & 0,92 \\
\hline 31 & Taquara & 57.238 & 21,2 & 0,37 \\
\hline \multirow[t]{2}{*}{32} & Três Coroas & 260.92 & 13,1 & 0,50 \\
\hline & TOTAL & 2.206 .927 & $1.531,2$ & 0,62 \\
\hline
\end{tabular}

*Municipios que não integram o Consórcio Pró-Sinos.

Fonte: IBGE, 2015; Pró-Sinos, 2012. 
A Fig. 2 demonstra ainda o volume de resíduos gerados em toneladas por dia e a média gerada de RSU por habitante.dia ${ }^{-1}$, conforme o Plano Regional de Gestão Integrada de Resíduos Sólidos dos Municípios Integrantes do Consórcio Público de Saneamento da Bacia Hidrográfica do Rio dos Sinos, Pró-Sinos (PRÓ-SINOS, 2012). Para os demais municípios fez-se uso da média da geração entre os entes do Consórcio.

De acordo com Hasse (2003), as atividades econômicas relacionadas à Bacia Hidrográfica se concentram no turismo, na indústria moveleira e no comércio na região serrana, principalmente nos municípios de Gramado, Canela e São Francisco de Paula. Na porção média, as atividades de maior expressão são o setor coureiro-calçadista, seguido de serviços. Destacam-se nesse cenário os municípios de Três Coroas, Igrejinha, Sapiranga, Novo Hamburgo e Portão.

Ainda na região central, o município de Taquara se destaca na atividade de comércio. Na porção baixa ou inferior da bacia, incluindo principalmente os municípios de São Leopoldo, Sapucaia do Sul e Canoas, destacam-se os setores metalmecânico, alimentício e petroquímico. Nesta última região verifica-se também o alto grau de urbanização; o do município de Sapucaia do Sul, por exemplo, concentra cerca de $2.144 \mathrm{hab} / \mathrm{km}^{2}$ (GOETZE, 2009). A localização espacial da Bacia Hidrográfica e dos municípios constituintes apresenta-se na Fig. 2.

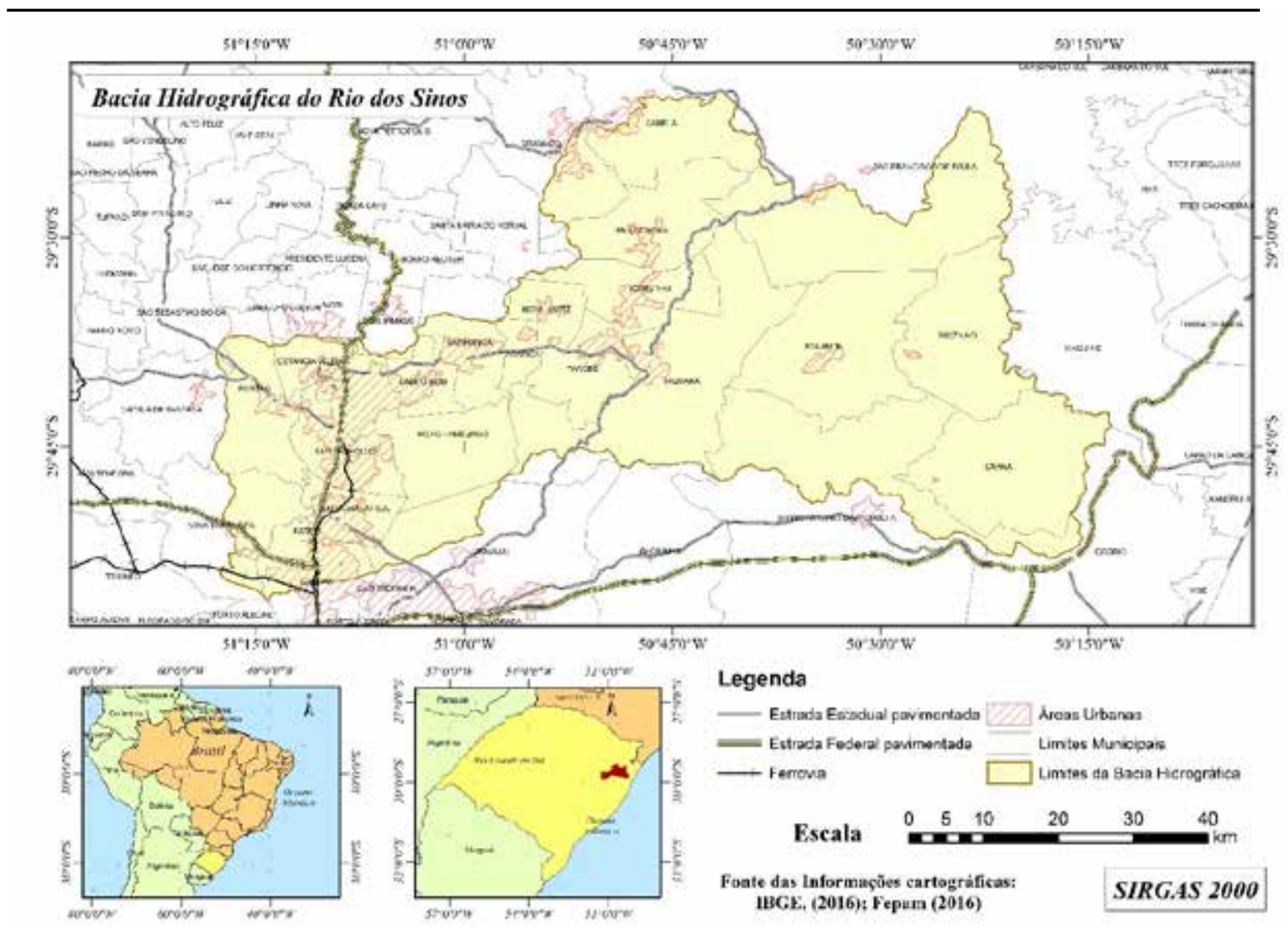

Figura 2: Municípios e limites da bacia Hidrográfica do Rio dos Sinos Fonte: FEPAM, 2015; IBGE 2015; ANA, 2015. 
Observando a disposição geográfica dos municípios da Bacia Hidrográfica do Rio dos Sinos, percebe-se que as maiores concentrações de áreas urbanizadas situam-se na região sudoeste, estendendo-se em direção à região central. Considerando as regiões a montante (sentido do fluxo hídrico), onde se localizam os municípios de Rolante, Caraá e Riozinho, a densidade populacional chega a $89,3 \mathrm{hab} / \mathrm{km}^{2}$, sendo ainda a região que apresenta maiores declividades.

Como salientado anteriormente, nem todos os municípios possuem integralmente suas áreas inseridas na Bacia Hidrográfica do Rio dos Sinos. Um exemplo são os municípios de Santo Antônio da Patrulha e Glorinha, os quais não possuem áreas urbanas inseridas na Bacia. Em outro caso, destacam-se os municípios de Gramado, Canela e São Francisco de Paula, os quais possuem apenas parte de suas áreas urbanas inseridas na Bacia.

Zveibil (2001) descreve que a distância do aterro sanitário ao centro da área de coleta não deve ultrapassar $25 \mathrm{~km}$. O percurso afeta, segundo os autores, o custo com o transporte, atraso de roteiros e maior tempo de exposição nos resíduos em vias públicas. Além disso, as condições de tráfego rodoviário em grandes cidades dificultam o deslocamento, sendo indicadas, nesse caso, estações de transbordo ou áreas de transferência de resíduos.

Devido ao fato de a localização de áreas para aterros sanitários consorciados não ter sido realizada previamente, este estudo baseou-se na premissa de que essa área poderia se localizar em qual- quer ponto em um raio de $10 \mathrm{~km}$. Dessa forma, o percurso máximo atingido seria de $20 \mathrm{~km}$ entre o ponto mais distante de coleta e o aterro sanitário consorciado. Restam, neste caso, ainda uma tolerância de $5 \mathrm{~km}$ para os roteiros, uma vez que eles nem sempre seguem rotas diretas aos aterros.

A partir desta premissa, foram realizados arranjos intermunicipais em um raio estipulado de $10 \mathrm{~km}$, visando atingir um número mínimo de 200.000 habitantes para cada proposta de gerenciamento Consorciado, apoiado nos conceitos de Barros et al., (2014) e Neto et al., (2011), os quais relacionam a viabilidade para produção de Biogás como fonte de energia para geração de eletricidade e os custos de implantação de aterros sanitários conforme o número de habitantes, respectivamente.

Os exemplos apresentados a seguir, na Fig. 3, demonstram 5 arranjos, os quais englobam mais de um município. É possível observar também que o município com localização geográfica desfavorável para gerenciamento consorciado na área de abrangência da Bacia Hidrográfica é Caraá.

Outros municípios, como Gramado, Canela e São Francisco de Paula, possuem a área urbana transpassada pelo divisor de águas da Bacia, e sua localização espacial também inviabilizou a cooperação em função de distância. Contudo, a gestão consorciada poderia ser vislumbrada entre esses municípios, objetivando redução de custos para disposição final, frente à proximidade das regiões urbanizadas. 


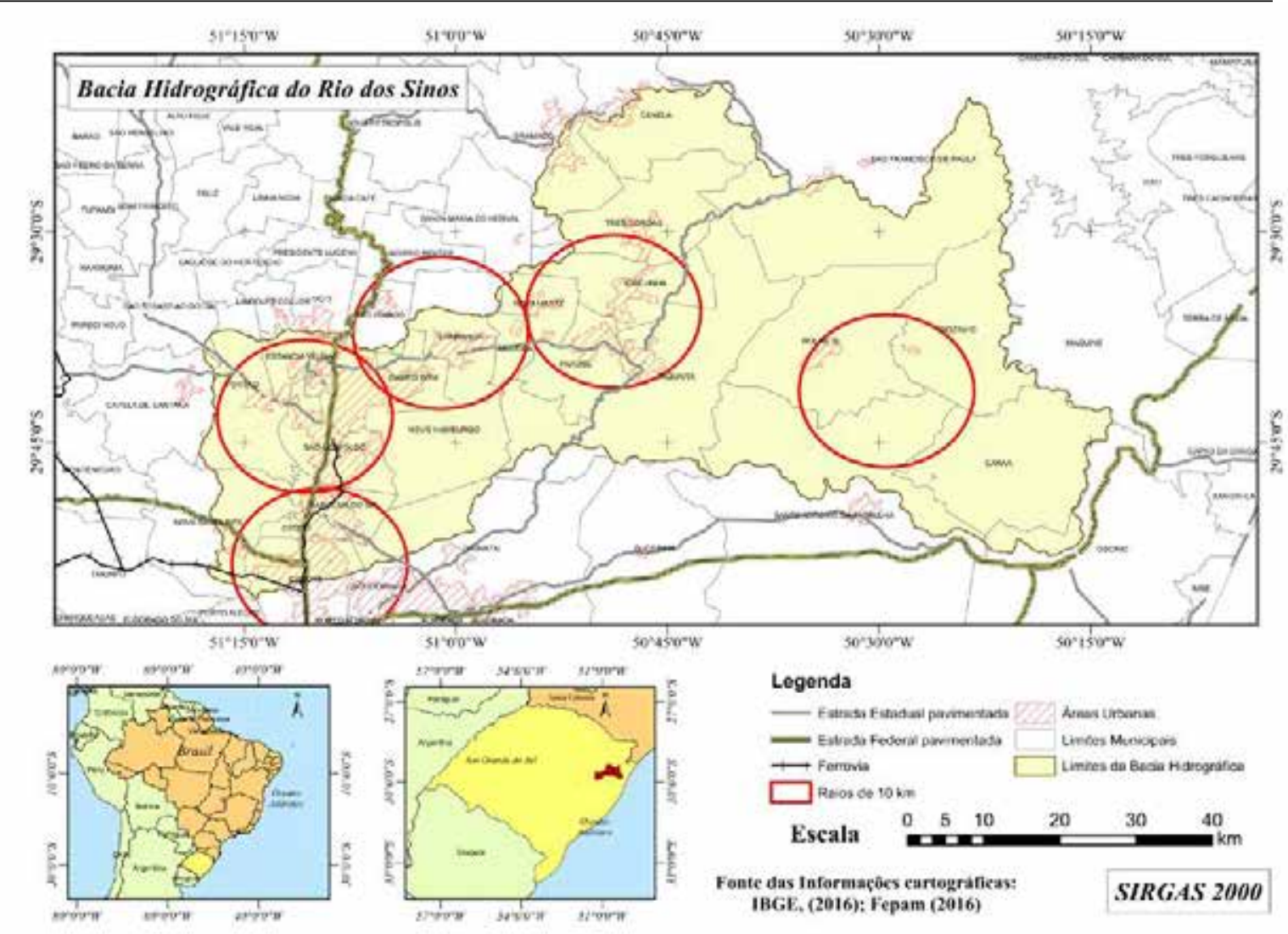

Figura 3: Raios de 10 km englobando os municipios da bacia Hidrográfica Fonte: FEPAM, 2015; IBGE 2015; ANA, 2015.

Outra questão se refere aos municípios de Rolante e Riozinho, os quais também abrigam um número pequeno de habitantes para a finalidade pretendida (25.283 hab). Soma-se a essa questão a localização geográfica também desfavorável à implantação de aterro sanitário consorciado para fins energéticos. Mesmo assim, a associação poderia reduzir os custos no gerenciamento do transporte e na destinação final de resíduos sólidos urbanos, quando comparada a ações individuais.
O município de Santo Antônio da Patrulha possui $100 \%$ de sua área urbana fora da Bacia $\mathrm{Hi}$ drográfica do Rio dos Sinos, e seu posicionamento espacial também inviabilizou a adesão à proposta. Diferente desse caso é o do município de Dois Irmãos, que apesar da área urbana estar fora dos limites da Bacia, foi favorecido pelo posicionamento, proporcionando sua união aos municípios vizinhos. A Tabela 2, a seguir, apresenta a relação dos Consórcios vislumbrados neste estudo. 
Tabela 2: Arranjos intermunicipais propostos.

\begin{tabular}{|c|c|c|}
\hline Consórcio 1 & População (hab) & Volume (t.ano-1) \\
\hline Cachoeirinha & 125.975 & 24.897 \\
\hline Canoas & 341.343 & 102.200 \\
\hline Esteio & 83.984 & 18.480 \\
\hline Nova Santa Rita & 25.700 & 7.300 \\
\hline Sapucaia do Sul & 138.357 & 43.800 \\
\hline Total: & $\mathbf{7 1 5 . 3 5 9}$ & $\mathbf{1 9 6 . 6 7 7}$ \\
\hline Consórcio 2 & População (hab) & Volume (t.ano-1) \\
\hline Estância Velha & 46.444 & 6.935 \\
\hline Novo Hamburgo & 248.694 & 65.700 \\
\hline Portão & 33.994 & 4.500 \\
\hline São leopoldo & 228.370 & 62.050 \\
\hline Total: & $\mathbf{5 5 7 . 5 0 2}$ & $\mathbf{1 3 9 . 1 8 5}$ \\
\hline
\end{tabular}

\begin{tabular}{|c|c|c|}
\hline Consórcio 3 & População (hab) & Volume (t.ano-1) \\
\hline Araricá & 5.301 & 730 \\
\hline Campo Bom & 64.171 & 9.709 \\
\hline Dois Irmãos & 30.175 & 5.986 \\
\hline Sapiranga & 79.560 & 17.155 \\
\hline Total: & $\mathbf{1 7 9 . 2 0 7}$ & $\mathbf{3 3 . 5 8 0}$ \\
\hline & & \\
\hline Consórcio 4 & População (hab) & Volume (t.ano-1) \\
\hline Igrejinha & 34.341 & 9.490 \\
\hline Nova Hartz & 20.035 & 2.920 \\
\hline Parobé & 55.486 & 13.870 \\
\hline Taquara & 57.238 & 7.388 \\
\hline Total: & $\mathbf{1 6 7 . 1 0 0}$ & $\mathbf{3 3 . 6 6 8}$ \\
\hline
\end{tabular}

Como demonstra a Tabela 3, os Consórcios 1 e 2 englobam o maior número de habitantes e consequentemente maior volume de resíduos, conforme os arranjos propostos. Esse cenário condiz com o de Goetze (2009), quando a autora salienta o alto grau de urbanização da região inferior da Bacia Hidrográfica do Rio dos Sinos, justamente onde se localizariam os consórcios com maior número de habitantes.

A metodologia proposta, onde estipulou-se a união intermunicipal de forma que houvesse um número mínimo de 200.000 habitantes por consórcio, mostrou-se adequada em dois casos, reunindo 9 dos 26 municípios da Bacia. Porém tornase importante destacar que apenas essas duas propostas reúnem 1.272.861 habitantes, correspondendo a aproximadamente $70 \%$ do número total de habitantes dos municípios avaliados.

Basicamente as propostas 3 e 4 se referem aos municípios da região central da bacia hidrográfica. Apesar de os arranjos não atingirem o número adotado como mínimo em habitantes, as relações estão próximas, ficando cerca de $10 \%$ abaixo no Consórcio 3 e aproximadamente 15\% no Consórcio 4. Os arranjos 3 e 4 contabilizam juntos cerca de $19 \%$ da população dos municípios avaliados, somando 346.307 habitantes, justificando assim a manutenção desses consórcios neste estudo.

Considerando um crescimento populacional médio de 1,03\% ao ano (Arranjo 3) e 1,01\% ao ano (Arranjo 4) (PRO-SINOS, 2012), o número de 200.00 habitantes seria atingido em 2022 e 2030, respectivamente. Diante desse cenário, considerando as quatro propostas e que o manejo adequado quanto à disposição final seria atendido em médio prazo para cerca de $90 \%$ da população.

Henriques (2004) dimensionou o aproveitamento energético do biometano (biogás separado do $\mathrm{CO}_{2}$ em função de rendimento) gerado em aterros sanitários. Para tanto, considerou os seguintes fatores: volume de RSU em giga toneladas; 6,5\% $\mathrm{CH}_{4} / \mathrm{t} \mathrm{RSU;} 1,4$ para densidade dos resíduos; 10,76 como fator de conversão de $\mathrm{Kw} / \mathrm{h} / \mathrm{m}^{3} \mathrm{CH}_{4}$; Fator de capacidade da planta de biometano de $80 \%$ e $35 \%$ de eficiência da planta de ciclo aberto. Utilizando-se desses mesmo fatores para as propostas de consórcio, obtém-se os resultados expressos na Tabela 3. 
Tabela 3: Potencial de geração de Energia elétrica.

\begin{tabular}{|c|c|c|c|c|c|c|}
\hline Arranjos & $\begin{array}{c}\text { RSU } \\
\text { (Gt/ano) }\end{array}$ & $\begin{array}{c}\text { Produção de } \\
\mathbf{C h}_{\mathbf{4}} \text { /ton }\end{array}$ & $\begin{array}{c}\text { Densidade/ } \mathbf{t} \text { / } \\
\mathbf{m}^{\mathbf{3}-\mathbf{1 , 4}}\end{array}$ & $\begin{array}{c}\text { Conversão } \\
\text { KWh /m }\end{array}$ & $\begin{array}{c}\text { Capacidade } \\
\text { operacional 80\% }\end{array}$ \\
\hline Consórcio 1 & 0,196 & 0,0127 & 0,017 & 0,192 & 0,154 \\
\hline planta (TWh/ano)
\end{tabular}

Considerando o Tabela 3, a partir da metodologia proposta por Henriques (2004), os consórcios unidos teriam uma capacidade de geração de energia elétrica de 0,276 TWh/ano. Barros, Filho e Silva (2014) avaliaram quatro cenários de consumo por habitante.ano-1, com base nos dados da Empresa de Pesquisa Energética - EPE. Os valores apontam para um consumo de energia per capita por ano (KWh/habitante.ano) médio entre os cenários de $4.294 \mathrm{KWh} / \mathrm{hab} / \mathrm{ano}$.

Com base nesse cenário e realizadas as devidas conversões, os consórcios teriam a capacidade de geração de 276.450 .000 kWh/ano. Dessa forma, teoricamente, baseado nos estudos de Barros, Filho e Silva (2014), a gestão consorciada proporcionaria a possibilidade de abastecimento com energia elétrica, por meio de micro usinas, a 64.380 habitantes.

Destaca-se claramente a necessidade de uma gama de estudos, projetos, avaliação de cenários, entre outros, para viabilizar potenciais instalações. De qualquer forma, esse quadro representaria aproximadamente $4 \%$ da população residente, abastecida por uma fonte renovável de energia.

Considerando ainda as tarifas homologadas pela Resolução da Agência Nacional de Energia Elétrica $n^{\circ} 2.059$ de 12 de abril de 2016, a operação do sistema na chamada bandeira amarela, para fornecimento residencial, sem considerar - Imposto sobre Circulação de Mercadorias e Serviços, ICMS, possui uma tarifa de $\mathrm{R} \$ 0,47202$ $\mathrm{kWh}$. Analogamente, esse valor representa
R\$ 130.489.929,00/ano pagos à concessionária de energia pelos usuários do sistema de geração de energia gerada a partir de biometano.

\section{CONCLUSÕES}

A análise realizada permitiu identificar os possíveis arranjos intermunicipais que apresentam potencial para gerir associativamente a disposição final de resíduos sólidos urbanos, com a possibilidade de recuperação energética e redução nos custos de instalação.

O cenário evidencia ainda a necessidade de avaliar primordialmente áreas aptas para a disposição final, podendo nesse caso consolidar ou não as opções dos consórcios propostos. Essa premissa se justifica, uma vez que áreas densamente povoadas podem estar com áreas próprias esgotadas, inviabilizando proposições de gerenciamento entre os entes federados.

Alguns municípios, a partir da metodologia proposta, tiveram sua inclusão descartada principalmente devido à localização geográfica. Porém a inviabilidade energética não impede estudos direcionados ao gerenciamento consorciado, ou ainda a inclusão de estações de transbordo. As possibilidades apresentadas demandam mais estudos para aproveitamento energético e para o gerenciamento, porém se apresentam como uma alternativa à descentralização da geração de energia elétrica, vislumbrando as potencialidades regionais e diversificando a matriz energética. 


\section{REFERÊNCIAS}

ABRELPE - Associação Brasileira de Empresas de Limpeza Pública e Resíduos Especiais. Panorama dos Resíduos Sólidos no Brasil 2014. São Paulo, ABRELPE, 2016.

ANEEL - Agência Nacional De Energia Elétrica. Resolução Homologatória N².059, de 12 de abril de 2016.

BARROS, R. M., FILHO, G. L. T.; SILVA, F. I. The electric energy potential of landfill biogas in Brazil. Energy Policy. V. 65, p. 150-164, Ed. Elsevier, 2014.

CHERTOW, M. Uncovering industrial symbiosis. Journal of Industrial Ecology, New Haven, 2007, v.1, n.1, 2007.

GHILANI, C. D.; WOLF, P.R.: Geomática. Tradução, Daniel Vieira; revisão técnica Alessandro Salles Carvalho. São Paulo. Pearson Education do Brasil. 698 p. Título Original: Elementary Surveying: an introdution to geomatics. 13 ed. 2013.

GOETZE. C.: Análise de cenários para o gerenciamento de resíduos sólidos domésticos recicláveis no horizonte do plano de gerenciamento da Bacia Hidrográfica do Rio dos Sinos. Dissertação (Mestrado em Engenharia Civil). Universidade do Vale do Rio dos Sinos. São Leopoldo RS. 2009.

HENRIQUES, R. M.; Aproveitamento Energético dos Resíduos Sólidos Urbanos: Uma Abordagem Tecnológica. 189 p., Dissertação (Mestrado em Engenharia). Universidade do Rio de Janeiro. Planejamento Energético. 2004.

IBGE - Instituto Brasileiro de Geografia e Estatística. Diretoria de Pesquisas - DPE - Coordenação de População e Indicadores Sociais - COPIS. Disponível em: http://www.cidades.ibge.gov.br/ xtras/home.php. Acesso em 28.nov.2015.

JUCÁ, J. F. T.: Análise das Diversas Tecnologias de Tratamento e Disposição Final de Resíduos Sólidos Urbanos no Brasil, Europa, Estados Unidos e Japão. Jaboatão dos Guararapes PE. Grupo de Resíduos Sólidos. UFPE, 2014.

NETO, J. C. da S.; DUARTE, P. A.; PFEIFFER, S. C.; COTRIN, S. L. da S.: Estimativa dos Custos de Implantação de Aterros Sanitários nas Bacias Dos Rios São Francisco e Parnaíba. Anais. $26^{\circ}$ Congresso
Brasileiro de Engenharia Sanitária e Ambiental. 25 a 29 de setembro - Porto Alegre. 2011.

PRO-SINOS - Consórcio Público de Saneamento Básico da Bacia Hidrográfica do Rio dos Sinos. Plano Regional de Gestão Integrada de Resíduos Sólidos dos municípios Integrantes do Consórcio Público de saneamento Básico da Bacia Hidrográfica do Rio dos Sinos Pró-Sinos (PRGIRS). São Leopoldo, 2012.

SANTOS, I. F.; BARROS, R. M.; FILHO, G. L. T.: Uma avaliação energética, econômica e ambiental das opções de aproveitamento energético do biogás deum aterro sanitário no Brasil. Revista do Centro de Ciências Naturais e Exatas - UFSM Santa Maria. -V. 19, n.21, mai-ago. 2015.

SEMA: Secretaria Estadual de Meio Ambiente. Estado do Rio Grande do Sul. Disponível em: http://www.sema.rs.gov.br/. Acesso em: 10 de novembro de 2016.

PINTO, V. M. S.; Ecologia Industrial: Existem empresas que não tem possibilidade de simbiose industrial? $1^{\circ}$ Internacional Workshop Advances in Cleaner Production. Anais. Universidade Estadual de Campinas. Nov/2007.

SMITH, M.; GOODCHILD, M; LONGLEY, P.: Geospatial Analysis. A Comprehensive Guide to Principles, Techniques and Software Tools. (5 ${ }^{\text {th }}$ edition). Published by The Winchelsea Press, Winchelsea, UK, 2015.

SUZUKI, J.A.N.; GOMES, J. Consórcios intermunicipais para a destinação de RSU em aterros regionais: estudo prospectivo para os municípios no Estado do Paraná. Engenharia Sanitária Ambiental, v.14, n.2, p. 155-15, abr./jun. 2009.

TANIMOTO, A. H.; KIPERSTOK A.: Proposta de Simbiose Industrial para Minimizar os Resíduos Sólidos no Polo Petroquímico de Camaçari. Anais. Congresso Brasileiro de Ciência e Tecnologia em Resíduos e Desenvolvimento Sustentável Costão do Santinho Florianópolis - Santa Catarina. 2004.

ZVEIBIL, V. Z. Manual de Gerenciamento Integrado de resíduos sólidos. Rio de Janeiro: IBAM, 2001. Disponível em: http://www. resol.com.br/cartilha4/index.php. Acesso em 24.jul.2017. 